\title{
Dr. Dr. h. c. Heinz Karger †
}

Dr. Heinz Karger, der Verleger unserer Zeitschrift, ist am 27. März, als er im Tessin Erholung suchte, im 64. Lebensjahr einem akuten Herz-infarkt erlegen. Bis zuletzt hatte er mit gewohnter Energie die Geschäfte seines Verlages und unserer Zeitschrift wahrgenommen. Sein unerwarteter Tod bedeutet für alle seine Mitarbeiter, so auch für uns, einen herben Schlag und schwer ersetzbaren Verlust.

Der Werdegang des alten, ursprünglichen Berliner Verlages und sein Neuaufbau in Basel seit 1937 sind bekannt und wurden vor kurzem eingehend gewürdigt. Wir alle, die wir die Genugtuung hatten, nach dem 2. Weltkrieg eine Internationale Zeitschrift unseres Faches mit Dr. Heinz Karger aufbauen zu dürfen, waren immer beeindruckt von seiner Hingabe und seiner Einsatzbereitschaft für eine solche große und mühe-volle Aufgabe. Die Gründung zahlreicher internationaler Archive, die die Fachgenossen des Kontinents und vieler außereuropäischer Lander verbinden, ist Dr. Kargers große Leistung. In Anerkennung seiner Ver-dienste verlieh ihm die Universität Basel anläßlich seines 60. Geburts-tages die Würde eines Doctor medicinae honoris causa.

Allzu früh ist uns Dr. Karger entrissen worden. Die Ausführung vieler Plane und neuer Aufgaben, die ihm vorschwebten, durfte er nicht mehr erleben. Wir alle, die mit ihm in ständigem Kontakt standen, wußten seine Klugheit, sein Verständnis für fachliche Probleme und seine stets entgegenkommende Art zu schätzen. Unser Dank gilt ihm über das Grab hinaus. Wir wissen, daß sein Sohn, der sein engster Mitarbeiter war und jetzt die Führung des Verlages übernommen hat, das Werk seines Vaters in seiner internationalen Geltung erfolgreich fortsetzen wird. Die Redaktion 